\title{
Bronchogenic cyst of the interatrial septum
}

\author{
Hui Jiang ${ }^{*}$, HuiShan Wang, HaiBo Wu and XinMin Li
}

\begin{abstract}
Bronchogenic cyst is considered as an uncommon congenital anomaly. It can be mostly found in mediastinum or lung. Intracardiac bronchogenic cyst is very rare. We found 2 cases in more than 20000 cardiac surgical cases in our department. The 2 cases bronchogenic cyst arose from interatrial septum (IAS), the preoperative diagnosis were myxoma, but the histological diagnosis were bronchogenic cyst in both cases. Although it is very rare, it should be considered while intracardiac tumor is diagnosed. It is recommended to complete resection of any bronchogenic cyst for primarily diagnostic and potentially therapeutic reasons, and every effort should be made to prevent complications due to injury to nearby tissues.
\end{abstract}

Keywords: Congenital anomaly, Bronchogenic cyst, Interatrial septum, Diagnosis, Therapy

\section{Background}

Bronchogenic cyst is considered as an uncommon congenital anomaly. It can be mostly found in mediastinum or lung. Intracardiac bronchogenic cyst is very rare. We found 2 cases in more than 20000 cardiac surgical cases in our department. The 2 cases bronchogenic cyst arose from interatrial septum (IAS), the preoperative diagnosis were myxoma, but the histological diagnosis were bronchogenic cyst in both cases. It is always misdiagnosed as the other intracardiac tumor.

\section{Case presentation}

Case 1

A 36-year-old woman with a short history of palpitation and mild dyspnea on exertion was admitted into our clinic, physical examinations and the chest radiograph were within normal ranges, echocardiography showed the ventricular and valve function were normal, a mass of $3.2 \times 2.7 \mathrm{~cm}$ attached to the IAS was discovered in the right atrium (Figure 1). The preoperative diagnosis was myxoma. The decision was made to resect the tumor. Under a median sternotomy and a standard cardiopulmonary bypass with cold blood cardioplegia, the right atrium was opened, a round cyst with a diameter of $3 \mathrm{~cm}$ arising from IAS

\footnotetext{
*Correspondence: jiangh33471@126.com

Department: Cardiovascular surgery, The Northern Hospital of Shenyang, No.83, Wenhua Road, Shenhe District, Shenyang, Liaoning Province 110016, China
}

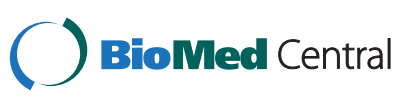

(c) 2013 Jiang et al.; licensee BioMed Central Ltd. This is an Open Access article distributed under the terms of the Creative Commons Attribution License (http://creativecommons.org/licenses/by/2.0), which permits unrestricted use, distribution, and reproduction in any medium, provided the original work is properly cited. was revealed, a $2.5 \mathrm{~cm}$ atrial septum defect was incidentally found behind the tumor, the lumen of the cyst contained yellow, jelly-like fluid, the cyst was resected completely after the fluid was sucked away, the defect was closed together with the ASD directly with 5/0 Prolene suture. Weaning from extracorporeal circulation was uneventful, the patient was discharged regularly on the $10^{\text {th }}$ day postoperative. No recurrence of the tumor was noted during the 5 year follow-up. Under microscopy, the cyst lining was ciliated columnar epithelium or so-called respiratory epithelium (Figure 2). Immunohistochemistry study showing CK $(+) 、 \operatorname{Vim}(+)$ 、actin $(-) 、$ s-100 (-). Histology diagnosis was bronchogenic cyst in the interatrial septum.

\section{Case 2}

Another 29-year-old woman with a history of palpitation and dyspnea on exertion in the last 4 months was referred to us. Systolic murmur was found by auscultation, the chest radiograph was also within normal ranges, echocardiography revealed a $2.5 \mathrm{~cm}$ ASD together with a $1.8 \times 1.9 \mathrm{~cm}$ mass attached to the IAS protruding into the left atrium. Computed Tomography showing a $2.5 \mathrm{~cm}$ ASD, a cyst of $2.0 \times 1.9 \mathrm{~cm}$ was found, the average attenuation value inside the left atria tumor was approximately $15 \mathrm{Hu}$ (Figure 3). The operation was performed similar as the previous one. The ASD was $2.5 \mathrm{~cm}$ of diameter, a $2.0 \mathrm{~cm}$ round cyst 


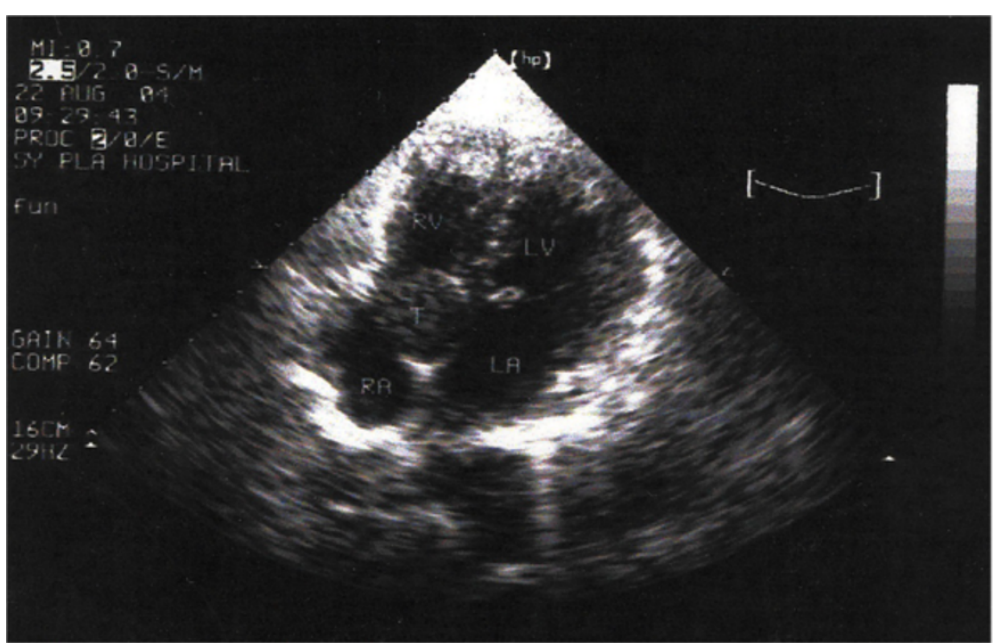

Figure 1 Transthoracic echocardiography showing a $3.2 \times 2.7 \mathrm{~cm}$ mass in the RA attached to interatrial septum. $(L A=l e f t$ atrium; $L V=$ left ventricle; $R A=$ right atrium; $R V=$ right ventricle; $T=$ tumor).

was incised completely. The defect together with the ASD was repaired with autologous pericardium. Annuloplasty was conducted at the commissure of the posterior and septal cusp due to mild tricuspid regurgitation. Macroscopically, the cyst consisted of a $0.2 \mathrm{~cm}$ wall. The lumen was filled with yellow, jelly-like fluid. Microscopically, the cyst was lined with ciliated columnar epithelium, resembling ciliated respiratory epithelium, and the cyst wall was composed of fibrous connective tissue (Figure 4). Immunohistochemistry study showed CK (+)、 $\operatorname{EMA}(+) 、 \operatorname{Vim}(+) 、 s-100$ (-)、CD68(-).

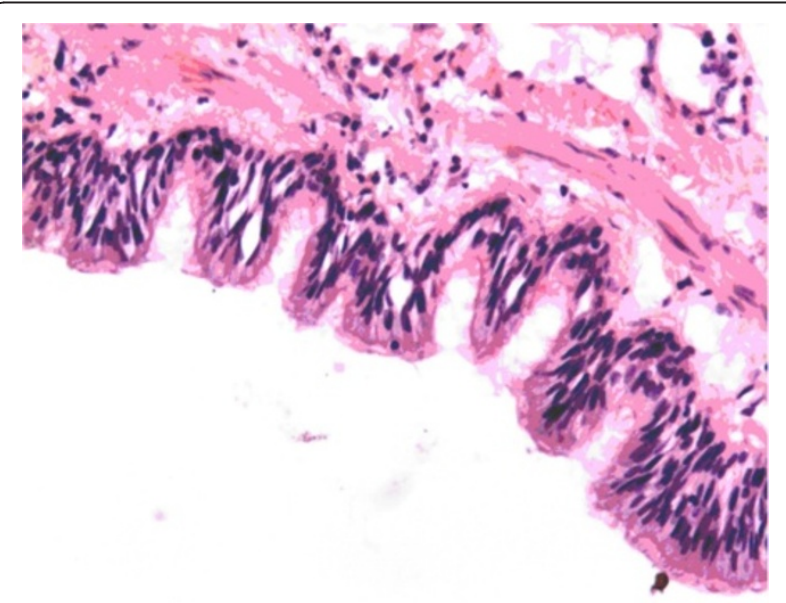

Figure 2 Cyst lined by ciliated columnar epithelium, the wall contains areas of fibroelastic tissue, smooth muscle cells. (Hematoxylin-eosin stain $\times 200$ ).
Postoperative course was uneventful, the patient was discharged 10 days post-operation. Echocardiography revealed no recurrence during the 3 years follow-up.

\section{Discussion}

The location of the bronchogenic cyst can be explained by embryogenesis. Bronchogenic cysts are believed to represent a localized portion of the tracheobronchial tree that becomes separated from normal airways during the branching process and does not undergo further development. Most probably develop between the $26^{\text {th }}$ and the $40^{\text {th }}$ day of intrauterine life, during the most active period of airway development. Cardiac primordia exist in a place very near to the foregut or primitive tracheobronchial tree. At this time, abnormal budding of the tracheobronchial tree may migrate to a myocardial location; bronchogenic cysts arise from such budding. Thus, cysts are usually at the pericardium, and it is very rare that tumors are in the interatrial septum $[1,2]$.

Intracardiac bronchogenic cysts are rare and are located on the epicardial surface or within the myocardium projecting into one of the cardiac cavities [3]. In the only review dealing with a larger number of intracardiac bronchogenic cysts, the majority were found in the right side of the heart, and only a few were located in the left side or their localization was not specified $[3,4]$. The location of the cyst in the two cases we reported was in the IAS, one protruding into the right atrium, the other projecting into the left atrium. 

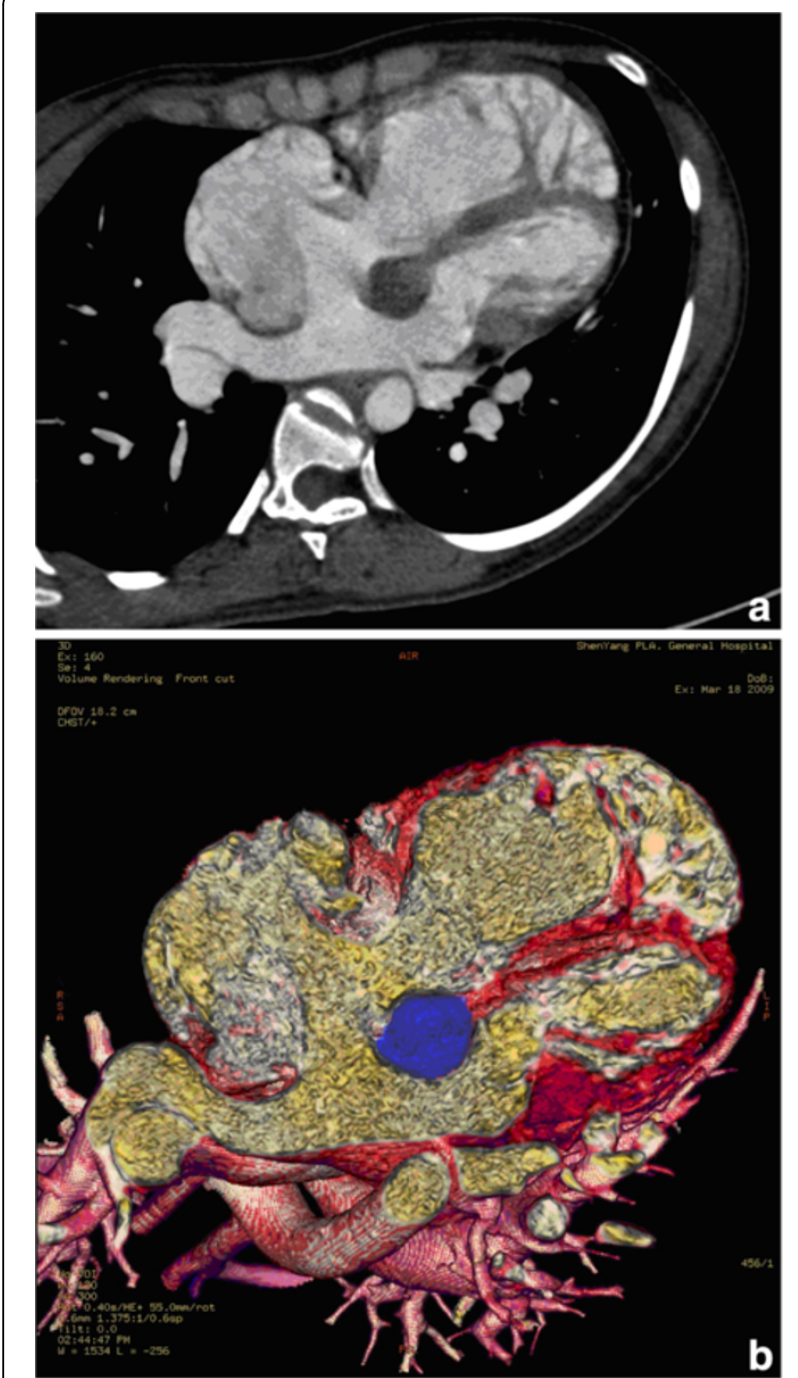

Figure 3 a,b Chest CT showing a $2.5 \mathrm{~cm}$ ASD, a $2.0 \times 1.9 \mathrm{~cm}$ mass projecting into the left atrium, the average attenuation value was approximately $15 \mathrm{Hu}$.

A bronchogenic cyst is a benign tumor. Many cases are asymptomatic with the lesions incidentally detected. Symptoms of intracardiac bronchogenic cysts such as chest pain, shortness of breath and arrhythmias can vary according to the location of the cyst, its size and compression of heart and vessels [1,5].

The tumor of the $1^{\text {st }}$ case we presented was larger than the ASD, the symptoms may come from the occlusion by the mass. But the ASD was bigger than the cyst in the $2^{\text {nd }}$ case, the symptoms may due to the ASD.

Most intracardiac bronchogenic cysts were found by transthoracic and transesophageal echocardiography, the diagnosis was made by contrast-enhanced chest helical CT and cardiac MRI and later was approved intraoperatively $[1,6]$.

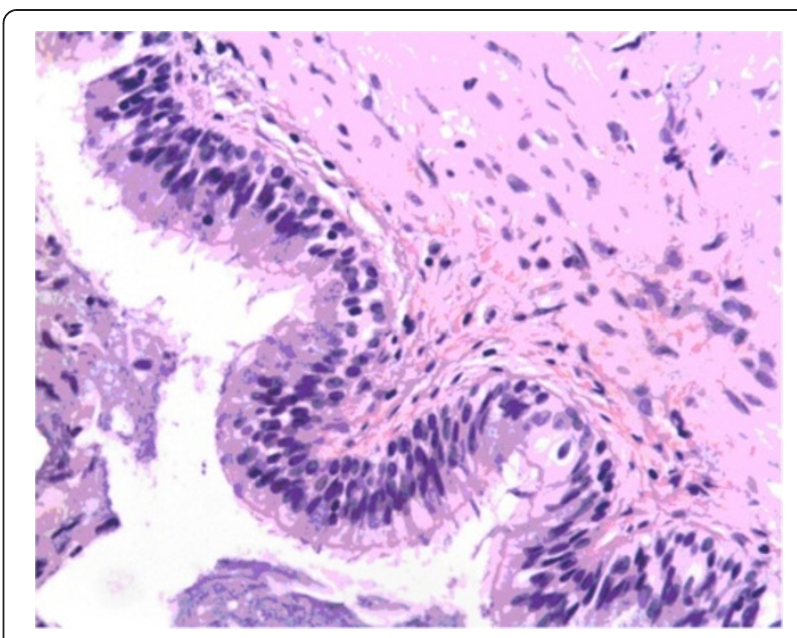

Figure 4 Hematoxylin-eosin stained photomicrograph (magnification $\times 200$ ) showing the cyst lining of ciliated columnar epithelium with interspersed goblet cells and surrounding fibrous connective tissue.

While considering an intracardiac tumor, myxoma, papillary fibroelastoma, thrombus, metastasis, etc. is usually considered. For a cystic tumor in the cardiac chamber, bronchogenic cyst should be in the differential diagnosis list $[3,6]$. The preoperative diagnosis of the two cases we reported were myxomas because bronchogenic cyst is rarely seen.

Bronchogenic cyst is a benign tumor, but definitive diagnosis should be made by pathology study. It is not possible to perform biopsy in the cardiac chamber because pulmonary or cerebral embolism may be resulted from the fluid contained. Bronchogenic cysts may develop into malignancy [7-9]. St-Georges et al. recommended all presumed bronchogenic cysts seen in the adult be resected because the majority will ultimately become symptomatic or complicated [10].

\section{Conclusions}

Although bronchogenic cyst of interatrial septum is very rare, it should be considered while intracardiac tumor is diagnosed. It is recommended to complete resection of any bronchogenic cyst for primarily diagnostic and potentially therapeutic reasons, and every effort should be made to prevent complications due to injury to nearby tissues.

\section{Consent}

Written informed consent was obtained from the patient for the publication of this report and any accompanying images. 


\section{Competing interests}

The authors declare that they have no competing interests.

\section{Authors' contributions}

$\mathrm{HJ}$ conceived, designed and drafted the manuscript, and performed the surgery. HSW involved in the clinical discussion of the cases. HBW was the consultant in charge of the patient's care. XML performed the surgery and collected the imaging data. All authors read and approved the final manuscript.

Received: 10 August 2012 Accepted: 3 July 2013

Published: 9 July 2013

\section{References}

1. Lee T, Tsai IC, Tsai WL, Jan YJ, Lee CH: Bronchogenic cyst in the left atrium combined with persistent left superior vena cava: the first case in the literature. AJR 2005, 185:116-119.

2. Kawase $Y$, Takahashi M, Takemura H, Tomita S, Watanabe G: Surgical treatment of a bronchogenic cyst in the interatrial septum. Ann Thorac Surg 2002, 74:1695-1697.

3. Weinrich M, Lausberg HF, Pahl S, Schäfers HJ: A bronchogenic cyst of the right ventricular endocardium. Ann Thorac Surg 2005, 79:e13-e14.

4. Wei X, Omo A, Pan TC, Li J, Liu LG, Hu M: Left ventricular bronchogenic cyst. Ann Thorac Surg 2006, 81:e13-e15.

5. Kobza R, Oechslin E, Jenni R: An intrapericardial bronchogenic cyst. Interact Cardiovasc Thorac Surg 2003, 2:279-280.

6. Azeem F, Rathwell C, Awad Wl: A near fatal presentation of a bronchogenic cyst compressing the left main coronary artery. J Thorac Cardiovasc Surg 2008, 135:1395-1396.

7. Endo C, Imai T, Nakagawa H, Ebina A, Kaimori M: Bronchioloalveolar carcinoma arising in a bronchogenic cyst. Ann Thorac Surg 2000, 69:933-935.

8. Jakopovic M, Slobodnjak Z, Krizanac S, Samarzija M: Large cell carcinoma arising in bronchogenic cyst. J Thorac Cardiovasc Surg 2005, 130:610-612.

9. Servais E, Paul S, Port JL, Altorki NK, Lee PC: Carcinoid tumor nested within a bronchogenic cyst. J Thorac Cardiovasc Surg 2008, 136:227-228.

10. St-Georges R, Deslauriers J, Duranceau A, Vaillancourt R, Deschamps C, Beauchamp $G$, et al: Clinical spectrum of bronchogenic cysts of the mediastinum and lung in the adult. Ann Thorac Surg 1991, 52:6-13.

doi:10.1186/1749-8090-8-171

Cite this article as: Jiang et al:: Bronchogenic cyst of the interatrial septum. Journal of Cardiothoracic Surgery 2013 8:171.

\section{Submit your next manuscript to BioMed Central and take full advantage of:}

- Convenient online submission

- Thorough peer review

- No space constraints or color figure charges

- Immediate publication on acceptance

- Inclusion in PubMed, CAS, Scopus and Google Scholar

- Research which is freely available for redistribution 